\title{
High-Performance Flexible Ultraviolet Photodetectors with Ni/Cu-Codoped ZnO Nanorods Grown on PET Substrates
}

\author{
Hafiz Muhammad Salman Ajmal, Fasihullah Khan ${ }^{\circledR}$, Noor U1 Huda, Sunjung Lee, Kiyun Nam, \\ Hae Young Kim, Tae-Hyong Eom and Sam Dong Kim * \\ Division of Electronics and Electrical Engineering, Dongguk University, Seoul 100-715, Korea \\ * Correspondence: samdong@dongguk.edu; Tel.: +82-2-2260-3800; Fax: +82-2-2277-8735
}

Received: 13 June 2019; Accepted: 23 July 2019; Published: 25 July 2019

\begin{abstract}
As a developing technology for flexible electronic device fabrication, ultra-violet (UV) photodetectors (PDs) based on a $\mathrm{ZnO}$ nanostructure are an effective approach for large-area integration of sensors on nonconventional substrates, such as plastic or paper. However, photoconductive $\mathrm{ZnO}$ nanorods grown on flexible substrates have slow responses or recovery as well as low spectral responsivity $\boldsymbol{R}$ because of the native defects and inferior crystallinity of hydrothermally grown $\mathrm{ZnO}$ nanorods at low temperatures. In this study, $\mathrm{ZnO}$ nanorod crystallites are doped with $\mathrm{Cu}$ or $\mathrm{Ni} / \mathrm{Cu}$ when grown on polyethylene terephthalate (PET) substrates in an attempt to improve the performance of flexible PDs. The doping with $\mathrm{Ni} / \mathrm{Cu}$ or $\mathrm{Cu}$ not only improves the crystalline quality but also significantly suppresses the density of deep-level emission defects in as-grown $\mathrm{ZnO}$ nanorods, as demonstrated by X-ray diffraction and photoluminescence. Furthermore, the X-ray photoelectron spectroscopy analysis shows that doping with the transition metals significantly increases the oxygen bonding with metal ions with enhanced $\mathrm{O} / \mathrm{Zn}$ stoichiometry in as-grown nanorods. The fabricated flexible PD devices based on an interdigitated electrode structure demonstrates a very high $R$ of $\sim 123 \mathrm{~A} / \mathrm{W}$, a high on-off current ratio of $\sim 130$, and a significant improvement in transient response speed exhibiting rise and fall time of $\sim 8$ and $\sim 3 \mathrm{~s}$, respectively, by using the $\mathrm{ZnO}$ nanorods codoped by $\mathrm{Ni} / \mathrm{Cu}$.
\end{abstract}

Keywords: Flexible UV detector; Ni/Cu codoping; $\mathrm{ZnO}$ nanorods; PET substrate; spectral responsivity

\section{Introduction:}

Flexible sensors using inorganic or organic nanostructures have been employed for various sensing applications, such as wearable prosthetics [1], organs-on-chips [2], and noninvasive pathology [3]. For this reason, high-performance flexible ultraviolet (UV) photodetectors (PDs) using nanostructured semiconductor oxides are also emerging as a potential candidate for future commercial and military applications, such as pollution monitoring, secure space communications, water purification, and missile plume detection. Recently, much research has been done on flexible UV PDs using hydrothermally grown zinc oxide $(\mathrm{ZnO})$ nanorods grown on plastic substrates $[4,5]$. However, in general, they reveal low crystallinity induced by the native defects emerging by a low thermal treatment during the post-annealing steps for hydrothermal growth of $\mathrm{ZnO}$ nanorods [6-8], thereby deteriorating the overall performance of PDs. Recently, control over the morphology, structure, and position of the nanorods has been demonstrated to improve the performance of PDs by tuning the experimental conditions of the growth process [9]; however, engineering the nanorod growth process via tuning the process parameters involves complicated device processing which can be neither reliable or reproducible in process condition. Therefore, the doping with transition metal impurities in 
$\mathrm{ZnO}$ nanorods has been studied as a viable alternative solution to improve the UV PD performance by orders of magnitude [10]. Furthermore, the $\mathrm{ZnO}$ nanostructure has emerged as a dominant host material for the doping of transition metals due to its versatile properties and potential applications. Apart from the UV sensor applications, metal-doped $\mathrm{ZnO}$ nanostructures have been investigated by many research groups recently for solar cells, light emitting diodes, water splitting, and hydrogen generation [11-13]. They demonstrated the impact of doping on the intrinsic defects, optical and electrical properties by varying the dopant concentrations in $\mathrm{ZnO}$ nanocrystalline structures.

Numerous bottom-up approaches have been explored for the preparation of doped and undoped $\mathrm{ZnO}$ nanorods, such as molecular beam epitaxy, thermal decomposition, sputtering, vapor phase epitaxy, spray pyrolysis, co-precipitation, and pulsed laser deposition [11-14]. Most of them either employ expensive and sophisticated laboratory facilities or are limited by high-temperature $\mathrm{ZnO}$ nanorods growth on organic substrates, such as textile fibers or plastic polymers. Therefore, a facile hydrothermal growth scheme for the synthesis of $\mathrm{ZnO}$ nanorods in aqueous solution has been extensively examined because of its reasonable thermal budget, reproducibility, and suitability for a scalable roll-to-roll fabrication [15]. Likewise, the synthesis of $\mathrm{ZnO}$ nanorods on organic substrates, for instance, polyethylene terephthalate (PET) as used in this work, needs to be accomplished at significantly low temperature because of their low thermal deformation temperature $\left(\sim 150{ }^{\circ} \mathrm{C}\right)$. Moreover, the hydrothermal technique provides a unique opportunity to dope as-grown nanorods with transition metals in a growth solution $[16,17]$.

The $4 s^{2}$ orbital of $\mathrm{Zn}$ in $\mathrm{ZnO}$ crystals contains two electrons, and they interact with and fill up the $2 p^{6}$ orbital of oxygen. For this reason, the stoichiometric $\mathrm{ZnO}$ with empty $4 s^{2} \mathrm{Zn}$ orbital and completely filled $2 p^{6} \mathrm{O}$ orbital ends up with an intrinsic semiconductor. However, $\mathrm{ZnO}$ grown hydrothermally is oxygen deficient in practice, which makes $\mathrm{ZnO}$ nanorods intrinsically $n$-type because of the ionization of excess $4 s^{2}$ electrons of $\mathrm{Zn}$. It has been accepted that the unintentional $n$-type nature of as-grown $\mathrm{ZnO}$ is caused by the presence of $\mathrm{Zn}$ interstitials or oxygen vacancies; however, the matter of precise cause of $n$-type conductivity is still a debatable subject. For example, the cause for this can be related to the unintentional incorporation of shallow donor impurities, such as hydrogen which can be present in almost all growth conditions [18]. An undesirable UV sensing phenomenon is often observed from the PDs based on $\mathrm{ZnO}$ nanorods prepared in pristine condition because of the enormous $n$-type carrier concentration and quick recombination rate of photo-excited electron-hole pairs. Therefore, doping with transition metals, such as $\mathrm{Mn}, \mathrm{Ni}$ and $\mathrm{Cu}$, may resolve this critical problem and produce a desirable optoelectronic material quality for high-sensitivity UV sensor applications [19-21]. The presence of transition metal ions in a $\mathrm{ZnO}$ host lattice can modify the electronic and magnetic characteristics of $\mathrm{ZnO}$ because of the exchange interaction of the electrons in $d$-orbitals of transition metals with the electrons of $\mathrm{ZnO}$ in $s$ and $p$ orbitals. Recently, much effort has been focused on pristine $\mathrm{ZnO}$ nanostructures grown on plastic substrates, but little work has been reported on UV PDs based on transition metal doped $\mathrm{ZnO}$ nanocrystals [22,23]. In particular, the progress of research on PD devices fabricated using $\mathrm{Ni} / \mathrm{Cu}$ codoped $\mathrm{ZnO}$ nanorods grown on plastic substrates has been very limited.

In this work, we synthesized two different UV PDs based on ZnO nanorods doped by $\mathrm{Ni}$ and $\mathrm{Cu}$ together or $\mathrm{Cu}$-only using a hydrothermal method to compare the UV photoresponse with that of the devices based on undoped $\mathrm{ZnO}$ nanorods. $\mathrm{Cu}$ and $\mathrm{Ni}$ have been primarily chosen because: (i) ions of these dopants can swap the $\mathrm{Zn}$ ions without making any cationic vacancy, and (ii) they hold tetrahedral sites in the host lattice of $\mathrm{ZnO}$ in order to generate the required divergent physical properties. Among the various transition metals, $\mathrm{Cu}$ dopants are especially interesting because of their electronic shell structure is comparable to the chemical and physical properties of $\mathrm{Zn}$. Cu impurities can improve the crystallinity of $\mathrm{ZnO}$ nanorods by suppressing the defects related to oxygen or zinc vacancies [24]. However, $\mathrm{Ni}$ dopants also have the advantage of the fair solubility of $\mathrm{Ni}^{2+}$ ions in $\mathrm{ZnO}$ tetrahedral coordinates because their ionic radius is comparable to that of $\mathrm{Zn}^{2+}[25,26]$. The possible substitution of $\mathrm{Zn}^{2+}$ by $\mathrm{Ni}^{2+}$ can allow easy charge separation and transportation in $\mathrm{ZnO}$ nanorods. 
In this study, we investigated the evolutionary change of nanorod crystalline quality pursued by addition of transition metal dopants into the $\mathrm{ZnO}$ nanocrystals. For this, we examined the morphological, structural, chemical, and optical characteristics of the nanorods grown atop the PET substrates. UV PDs with an interdigitated electrode (IDE) structure were fabricated in order to verify our analysis on the improvement of nanorod crystalline quality by the dopings, and important device parameters influenced by the nanorod material properties were measured and analyzed.

\section{Experimental Procedure}

To fabricate the IDE-type UV PDs based on ZnO nanorods, we used commercially available PET substrates of a $1.5 \times 1.5 \mathrm{~cm}^{2}$ dimension. The device fabrication process flow was briefly illustrated in the schematics of Figure 1. All the chemical reagents (analytically graded with high purity $>99 \%$ ) used in this experiment were from Sigma-Aldrich, South Korea, and used without further purification. Before beginning the device fabrication, we first cleaned the PETs by sonication in ethanol and isopropyl alcohol and rinsed them with de-ionized (DI) water (8-10 $\mathrm{min}$ ) sequentially to remove any organic contaminants from the surface. The substrates were dried in a clean room environment by purging with nitrogen gas followed by complete removal of moisture on a digital hot plate at $90-100{ }^{\circ} \mathrm{C}$ for $2 \mathrm{~min}$. The device process starts with the fabrication of IDE patterns using $\mathrm{Au} / \mathrm{Ti}$ metals and the subsequent spin coating of $\mathrm{ZnO}$ seed layer (SL), however, to attain a hydrophilic surface of the PET substrate, it is essential to achieve strong adhesion between the $\mathrm{Au} / \mathrm{Ti}$ thin films and substrates. For this purpose, we pretreated the substrate surface by $\mathrm{O}_{2}$ plasma beforehand to improve the surface adhesion by converting the surface state of PETs to hydrophilic. In this treatment, plasma exposure was maintained in a reactive ion etcher system for $5 \mathrm{~min}$ at $100 \mathrm{sccm} \mathrm{\textrm {O } _ { 2 }}$ flow rate, $100 \mathrm{~W}$ RF power, and $50 \mathrm{mTorr}$ pressure. We then subjected the substrates to a photolithography system (Karl Suss, MA6 mask aligner, $365 \mathrm{~nm}$ ) by employing a photoresist image-reversal technique to pattern IDEs and then loaded all patterned substrates into an electron-beam evaporator to deposit 100/30 nm Au/Ti films. After that, a metal lift-off was done in acetone using an ultra-sound bath sonicator to attain required IDE patterns on the PET substrates.

Fabricated PDs on PET substrates with IDE patterns are shown in Figure 2. The IDE pattern has a dimension of $238 \times 1000 \mu \mathrm{m}^{2}$ with 20 fingers ( $10 \mu \mathrm{m}$ width, $2 \mu \mathrm{m}$ spacing) as depicted in the bottom-right layout of Figure 2. As shown in the micrograph (bottom-left of Figure 1) of nanorod-arrays grown atop the IDE structure, many $\mathrm{ZnO}$ nanorods are cross-linked between Au electrodes by forming nanorod-nanorod bridging junctions after the completion of process.

We adopted an aqueous solution route for the nanorods growth on the IDEs comprising a spin-coating step of $\mathrm{ZnO} S \mathrm{~L}$ and the subsequent nanorod growth step in a growth solution. To prepare the SL growth, we first produced a colloidal solution of $20 \mathrm{~mm}$ concentration of zinc acetate dehydrate $\left[\mathrm{Zn}\left(\mathrm{CH}_{3} \mathrm{COO}\right)_{2} \cdot 2 \mathrm{H}_{2} \mathrm{O}\right]$ in an organic solvent of $n$-propyl alcohol $\left[\mathrm{C}_{3} \mathrm{H}_{8} \mathrm{O}\right]$ and placed it in an ambient temperature for $8-10 \mathrm{~h}$ to achieve a homogeneous SL solution. The solution was spun at $3000 \mathrm{rpm}$ for $30 \mathrm{~s}$ to deposit the SL on the substrate and was baked at $100{ }^{\circ} \mathrm{C}$ on a hotplate for $1 \mathrm{~min}$. This spin-coating was successively repeated seven times to produce a final thickness of $\sim 10 \mathrm{~nm}$ after post-bake as measured by our cross-sectional transmission electron microscopy (TEM) shown in a bottom-left inset of Figure 1. The SL-coated substrates were post-annealed on a hotplate at $140{ }^{\circ} \mathrm{C}$ for $20 \mathrm{~min}$ in an air ambient to evaporate any undesirable organic residuals and to form stable $\mathrm{ZnO}$ crystallites. Finally, we performed the growth of nanorods in the following way. For the growth of undoped $\mathrm{ZnO}$ nanorods, we prepared a homogeneous equimolar (25 mm molarity) solution of methenamine $\left[\mathrm{C}_{6} \mathrm{H}_{12} \mathrm{~N}_{4}\right]$ and zinc nitrate hexahydrate $\left[\mathrm{Zn}\left(\mathrm{NO}_{3}\right)_{2} \cdot 6 \mathrm{H}_{2} \mathrm{O}\right]$ in a glass beaker containing $250 \mathrm{~mL}$ DI water and stirred the growth solution for $1 \mathrm{~h}$ to ensure complete mixing. The substrates were immersed in the growth solution upside down at a temperature of $80^{\circ} \mathrm{C}$ for $4 \mathrm{~h}$. In the cases of $\mathrm{Cu}$ doped and Ni/Cu codoped $\mathrm{ZnO}$ nanorods, we prepared two separate batches of solutions containing $25 \mathrm{~mm}$ equimolar $\mathrm{C}_{6} \mathrm{H}_{12} \mathrm{~N}_{4}$ and $\mathrm{Zn}\left(\mathrm{NO}_{3}\right)_{2} \cdot 6 \mathrm{H}_{2} \mathrm{O}$. The growth solutions for $\mathrm{Cu}$ and $\mathrm{Ni} / \mathrm{Cu}$ dopings were respectively provided 
by introducing $2 \mathrm{~mm}$ copper acetate monohydrate $\left[\left(\mathrm{CH}_{3} \mathrm{COO}\right)_{2} \mathrm{Cu} \cdot \mathrm{H}_{2} \mathrm{O}\right]$ and $2 \mathrm{~mm}$ of nickel acetate tetrahydrate $\mathrm{Ni}\left(\mathrm{OCOCH}_{3}\right)_{2} \cdot 4 \mathrm{H}_{2} \mathrm{O}$ with $2 \mathrm{~mm}$ of $\left(\mathrm{CH}_{3} \mathrm{COO}\right)_{2} \mathrm{Cu} \cdot \mathrm{H}_{2} \mathrm{O}$ solutions in each batch.
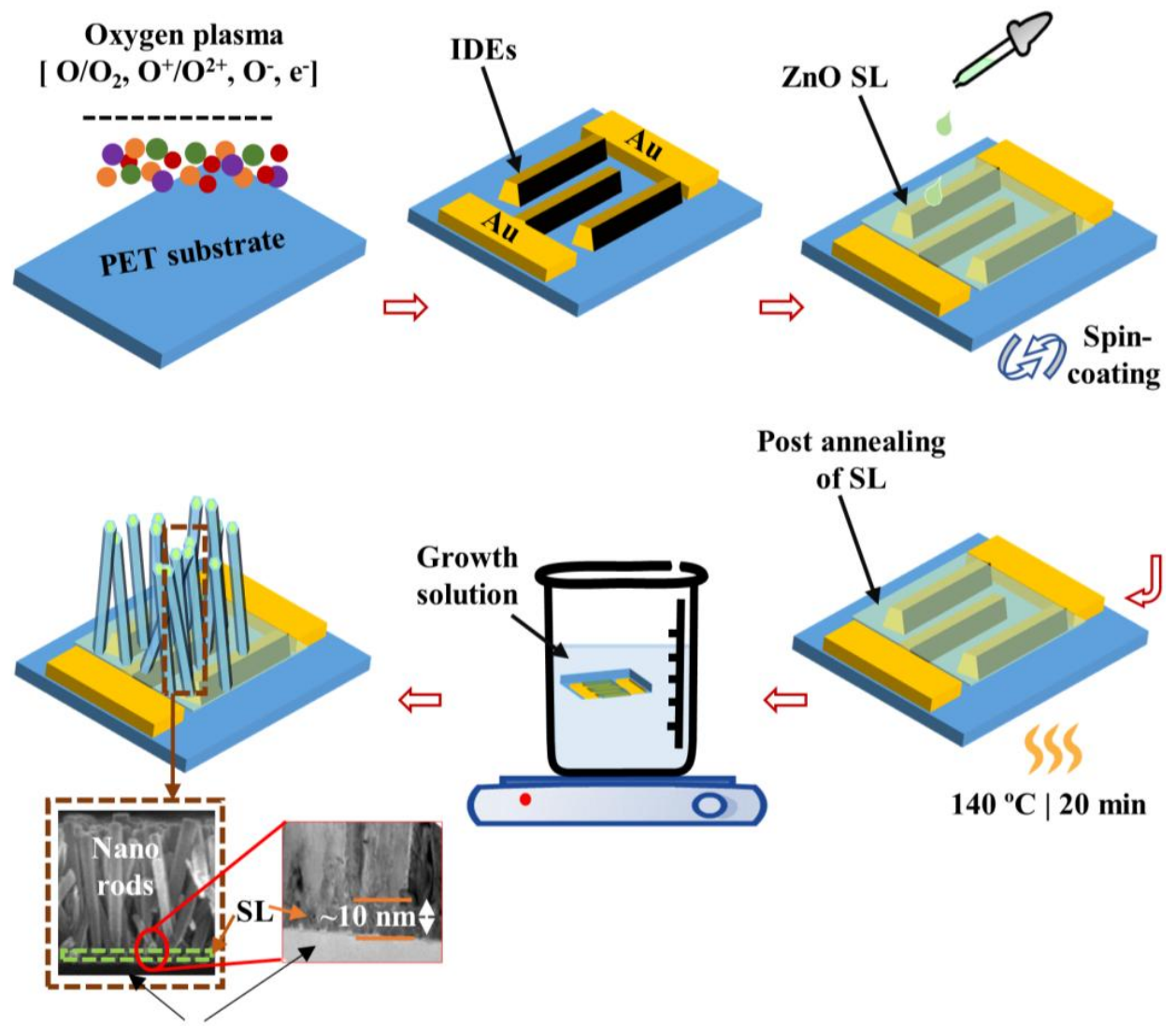

Post annealing

PET substrate

Figure 1. Schematic illustration of the process steps for zinc oxide $(\mathrm{ZnO})$ nanorods hydrothermal growth. Cross-sectional scanning electron microscopy and transmission electron microscopy (TEM) views of as-grown nanorods are shown in the bottom-left insets.

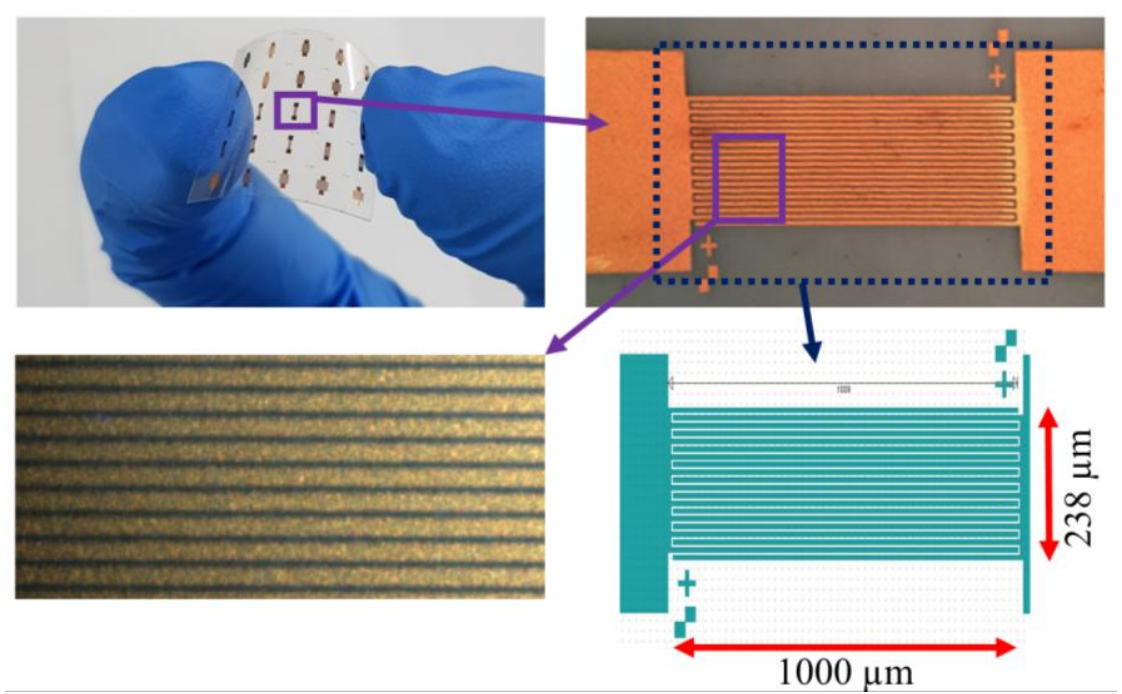

Figure 2. (Top-left) Fabricated flexible ultra-violet (UV) photodetectors(PDs) with interdigitated electrode (IDE) patterns. (Top-right) Magnified view of the fabricated PDs. (Bottom-left) Optical microscope image of $\mathrm{ZnO}$ nanorod-arrays grown on IDE structure. (Bottom-right) Layout of the IDE pattern for UV PDs. 
We examined the surface and cross-sectional morphologies of $\mathrm{ZnO}$ nanorods by field emission-scanning electron microscopy (FE-SEM, S-4800S Hitachi, Tokyo, Japan, $10 \mathrm{kV}$ ) and cross-sectional TEM (Hitachi, Tokyo, Japan, 9500 at $300 \mathrm{kV}$ ). The crystalline quality and preferred orientation of the nanorods were investigated by X-ray diffraction (XRD, D8 Advance spectrometer of Bruker, Billerica, MS, USA, AXS with $\mathrm{Cu} \mathrm{K} \alpha 0.1540 \mathrm{~nm}$ radiation). Evolutionary change in stoichiometry and chemical bonding state of the nanorods depending on doping was observed by $\mathrm{X}$-ray photoelectron spectroscopy (XPS, Jeol, Seoul, Korea) after cleaning the sample surface by ion milling $(\sim 10 \mathrm{~nm})$ using a PHI 5000 Versa Probe (Ulvac-PHI) spectrometer and a monochromator Al K $\alpha(1400 \mathrm{eV})$ anode $(25.0 \mathrm{~W}, 15 \mathrm{kV})$. To evaluate the optical characteristics of the nanorod crystallites, we carried out photoluminescence (PL, Hitachi, Tokyo, Japan) spectroscopy (Bio MFP-3D with $325 \mathrm{~nm}$ He-Cd laser) and UV-Visible absorbance spectroscopy (model T-60, Labindia, India) at room temperature. Photo-response current-voltage (I-V) characteristics, real-time transient characteristics upon UV on-off, and spectral responsivity of the fabricated PDs were measured by our measurement setup.

\section{Results and Discussion}

The geometry and the surface morphology of undoped, $\mathrm{Cu}$ doped, and $\mathrm{Ni} / \mathrm{Cu}$ codoped $\mathrm{ZnO}$ nanorods are shown in the SEM images of Figure 3a-c. As revealed in the top-view images, the nanorods were grown with fairly uniform distribution of diameters and the perfect hexagonal surface shape of wurtzite crystal structure. The measured average diameter was $\sim 80 \mathrm{~nm}$ in the case of undoped $\mathrm{ZnO}$ nanorods, and it was also shown that the PET surface was uniformly covered with as-grown $\mathrm{ZnO}$ nanorod-arrays. On the other hand, the diameters of $\mathrm{Cu}$ doped and $\mathrm{Ni} / \mathrm{Cu}$ codoped $\mathrm{ZnO}$ nanorod were increased up to $\sim 150$ and $\sim 166 \mathrm{~nm}$, respectively. Average length of the nanorod crystals was reduced from $\sim 670 \mathrm{~nm}$ (undoped) to $\sim 500$ and $\sim 530 \mathrm{~nm}$ in the case of $\mathrm{Cu}$ doping and $\mathrm{Ni} / \mathrm{Cu}$ codoping, respectively. Similar phenomenon of lateral crystal coarsening was observed in a number of earlier experiments by incorporating either $\mathrm{Ni}$ or $\mathrm{Cu}$ into the $\mathrm{ZnO}$ nanorods grown by solution-based method on Si substrates [25-29], and this phenomenon is supposed to be caused by promoted lateral growth associated with higher bond energy of transition metal-O than that of $\mathrm{Zn}-\mathrm{O}$ and reduced surface energy difference between polar and nonpolar planes $[25,28]$.

The nanorods were also grown preferentially in the vertical direction with higher surface density, as shown in cross-sectional SEM images of Figure $3 \mathrm{~d}-\mathrm{f}$, by the introduction of transition metal dopants into $\mathrm{ZnO}$ crystals. This SEM observation shows a good agreement with our XRD analysis. To examine the crystallographic structure and the degree of preferred orientation in growth direction, we performed a high-resolution XRD $2 \theta$ scan for the $\mathrm{ZnO}$ nanorods. As depicted in the XRD patterns of Figure 4 , all the observed diffraction peaks were in good agreement with standard indexes of JCPDS data (36-1451 card number). The most dominant peak was (002) reflection at $2 \theta=34.5^{\circ}$ in all samples examined in this study. This result indicates that the intrinsic growth characteristics of hexagonal-wurtzite $\mathrm{ZnO}$ nanorod crystals is aligned to the $c$-axis with a growth direction normal to the substrate. The (002) peak intensity was improved after $\mathrm{Cu}$ doping or $\mathrm{Ni} / \mathrm{Cu}$ codoping for the $\mathrm{ZnO}$ nanorods, which reveals the enhancement of (002) preferred growth orientation of our transition metal-doped $\mathrm{ZnO}$ nanorod crystals. Other reflections of relatively lower intensity from (100) and (101) planes were also observed at $31.7^{\circ}$ and $36.2^{\circ}$, respectively. As investigated in many earlier reports $[29,30]$, this (002) preferential growth of $\mathrm{ZnO}$ nanorod crystals is well known as an intrinsic property due to the lowest free surface energy $\left(1.6 \mathrm{~J} / \mathrm{m}^{2}\right)$ of $(002)$. In addition, no impurity traces or any other diffraction peak related to secondary phases from $\mathrm{Cu}, \mathrm{Cu}_{2} \mathrm{O}, \mathrm{CuO}, \mathrm{Ni}$, or $\mathrm{NiO}$ was detected within our XRD detection limit. This result suggests that $\mathrm{Ni}$ or $\mathrm{Cu}$ dopants used in this study did not form any new heterogeneous compound phases in the $\mathrm{ZnO}$ crystal but dissolved into the lattice matrix as a dopant [31]. 


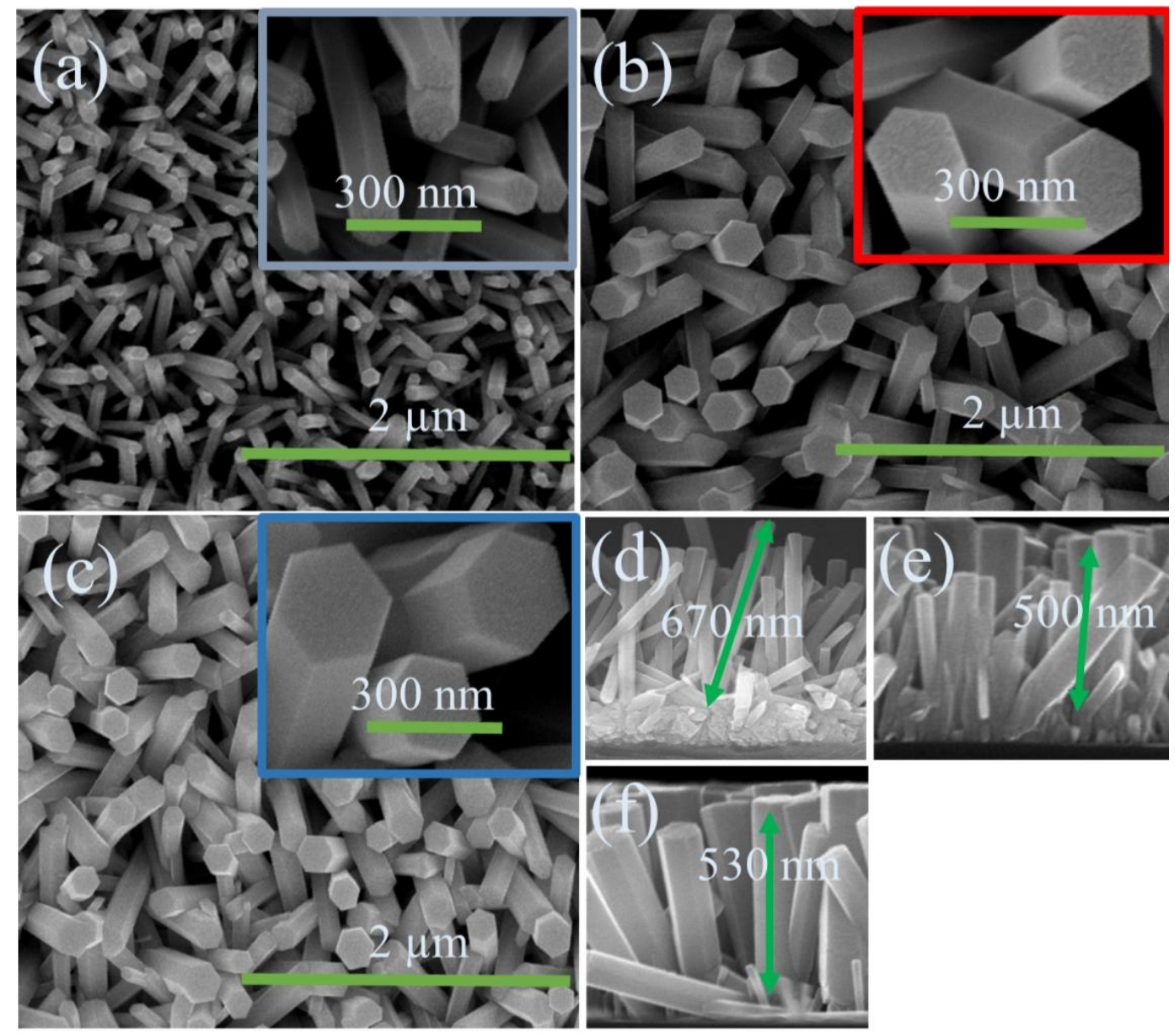

Figure 3. Scanning electron microscopy (SEM) top views of (a) undoped, (b) Cu doped, and (c) Ni/Cu codoped $\mathrm{ZnO}$ nanorods grown on polyethylene terephthalate (PET) substrates. Cross-sectional views of the $\mathrm{ZnO}$ nanorods grown under each condition are also shown in (d), (e) and (f).

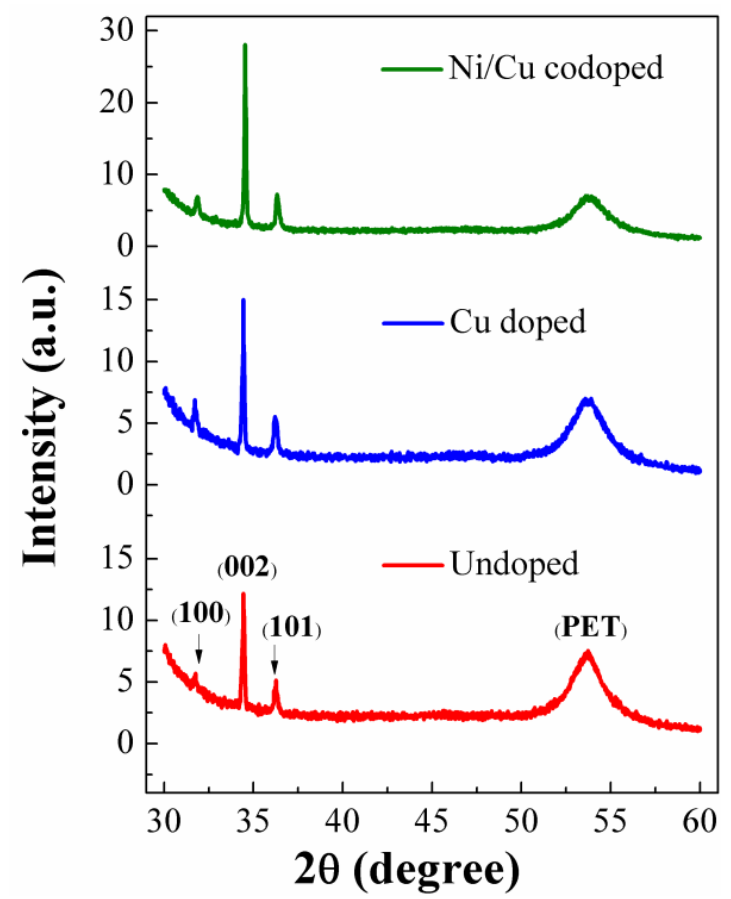

Figure 4. X-ray diffraction (XRD) $2 \theta$ patterns of as-grown $\mathrm{ZnO}$ nanorods. 
We summarized in Table 1 the full width at half maximum (FWHM) at (002) diffraction peak with corresponding peak position ( $2 \theta)$, lattice constant $c$, and the calculated degree of orientation from XRD spectra for each sample. As shown in the table, the (002) FWHM was significantly decreased with $\mathrm{Cu}$ doping, and it was decreased to about $1 / 2$ of the value of undoped sample after Ni/Cu codoping, in particular. This proposes that our transition metal doping, especially Ni/Cu codoping, plays a significant role in improving the crystalline quality of our $\mathrm{ZnO}$ nanorods crystals grown on PET substrates. Furthermore, the (002) $2 \theta$ positions of $\mathrm{Cu}$ doped and $\mathrm{Ni} / \mathrm{Cu}$ codoped samples showed slight shifts $\left(\sim 34.46^{\circ}\right.$ and $\left.\sim 34.48^{\circ}\right)$ toward higher angles compared to undoped sample $\left(\sim 34.45^{\circ}\right)$. This observation agrees with the previous experimental reports of possible replacements of $\mathrm{Zn}^{2+}$ by either $\mathrm{Cu}^{2+}$ or $\mathrm{Ni}^{2+}$ in the host $\mathrm{ZnO}$ lattice without changing the crystal structure. The minor shift in the position of (002) reflection arises because the radii of $\mathrm{Ni}(0.69 \AA)$ and $\mathrm{Cu}(0.73 \AA)$ are smaller than that of $\mathrm{Zn}^{2+}(0.74 \AA)$ ions $[25,32]$. This phenomenal substitutions of $\mathrm{Cu}$ or $\mathrm{Ni}$ dopants in the $\mathrm{ZnO}$ wurtzite hexagonal lattice can also induce a change in lattice parameter $c$ because of compact $\mathrm{CuZnO}_{4}$ units or shorter bonds of $\mathrm{CuZn}-\mathrm{O}$ in $\mathrm{Cu}$ doped $\mathrm{Zn}-\mathrm{Ni}-\mathrm{O}$ material [33]. The value of $c$ for the hexagonal structure can be calculated using the following expression [34]:

$$
\frac{1}{d^{2}}=\frac{4}{3}\left(\frac{h^{2}+h k+k^{2}}{a^{2}}\right)+\frac{l^{2}}{c^{2}}
$$

where $d$ is the spacing between the lattice, $h, k$, and $l$ represent the miller indices, and $a$ and $c$ are the cell lattice parameters. The $0.19 \%$ decrease in lattice constant $c$ with the introduction of $\mathrm{Cu}$ or $\mathrm{Ni} / \mathrm{Cu}$ dopants may arise from the replacement of $\mathrm{Zn}^{2+}$ ions by either $\mathrm{Cu}^{2+}$ or $\mathrm{Ni}^{2+}$ and their corresponding ionic-radii mismatch [35]. Furthermore, The degree of preferred orientation $F(h k l)$ was calculated using the following equation [36],

$$
F(h k l)=\left(P(h k l)-P_{0}(h k l)\right) /\left(1-P_{0}(h k l)\right.
$$

where $P(h k l)=I(h k l) / \Sigma I(h k l), P_{0}(h k l)=I_{0}(h k l) / \Sigma I_{0}(h k l), I(h k l)$ is the measured intensity of the diffraction peak reflected from the $(h k l)$ plane, and $I_{0}(h k l)$ is the intensity of the reference peak of the ( $h k l$ ) plane given by JCPDS (36-1451). The $F(002)$ calculations in Table 1 show that the $c$-axis alignment of synthesized nanorods was improved after $\mathrm{Cu}$ or $\mathrm{Cu} / \mathrm{Ni}$ doping.

Table 1. XRD key parameters extracted from undoped, $\mathrm{Cu}$ doped, and $\mathrm{Ni} / \mathrm{Cu}$ codoped $\mathrm{ZnO}$ nanorod crystals.

\begin{tabular}{ccccc}
\hline Sample & $\mathbf{( 0 0 2 )}$ 20 Position $\left(^{\circ}\right)$ & FWHM $\left.^{(}{ }^{\circ}\right)$ & $c(\AA)$ & Degree of (002) Orientation \\
\hline Undoped & 34.45 & 0.19 & 5.20 & 0.45 \\
Cu doped & 34.46 & 0.13 & 5.20 & 0.55 \\
$\mathrm{Ni} / \mathrm{Cu}$ codoped & 34.48 & 0.09 & 5.19 & 0.66 \\
\hline
\end{tabular}

Structural defects such as $\mathrm{O}$ vacancies or metal interstitials can significantly influence the optical characteristics of oxide nanostructures. As-grown wurtzite nanostructure crystallites of $\mathrm{ZnO}$ exhibit, in general, pretty good optoelectronic properties among the wide band-gap semiconductors; nonetheless, the luminescence properties of $\mathrm{Ni} / \mathrm{Cu}$ codoped $\mathrm{ZnO}$ nanocrystals grown on plastic substrates prepared at a low temperature have been rarely explored. PL characterization at room temperature is one of the most efficient ways to evaluate the defect states and crystalline quality of synthesized $\mathrm{ZnO}$ nanorod crystals. Figure 5a shows the measured PL spectra, and they have two prominent emission zones of a sharp UV emission region with a span of 366-400 nm and the other region of broad-band emission in the visible range $(400-800 \mathrm{~nm})$. The UV emission spectra of near-band emission (NBE) originates from the band-to-band excitonic recombination in $\mathrm{ZnO}$ crystals [37]. Significantly improved UV emissions recorded from the transition metal-doped nanocrystals can represent their enhanced crystalline quality; especially in the case of $\mathrm{Ni} / \mathrm{Cu}$ codoping, a very pronounced 
increase in NBE was shown in the spectra. Peak positions of NBE in each case of undoped, Cu doped, and $\mathrm{Ni} / \mathrm{Cu}$ doped $\mathrm{ZnO}$ nanorods were 372, 371, and $376 \mathrm{~nm}$, respectively. This slight difference in the emission wavelength is known to arise from various phenomena, such as the localization of charge carriers, electron phonon coupling, and lattice distortion in $\mathrm{ZnO}$ crystals $[33,38]$.
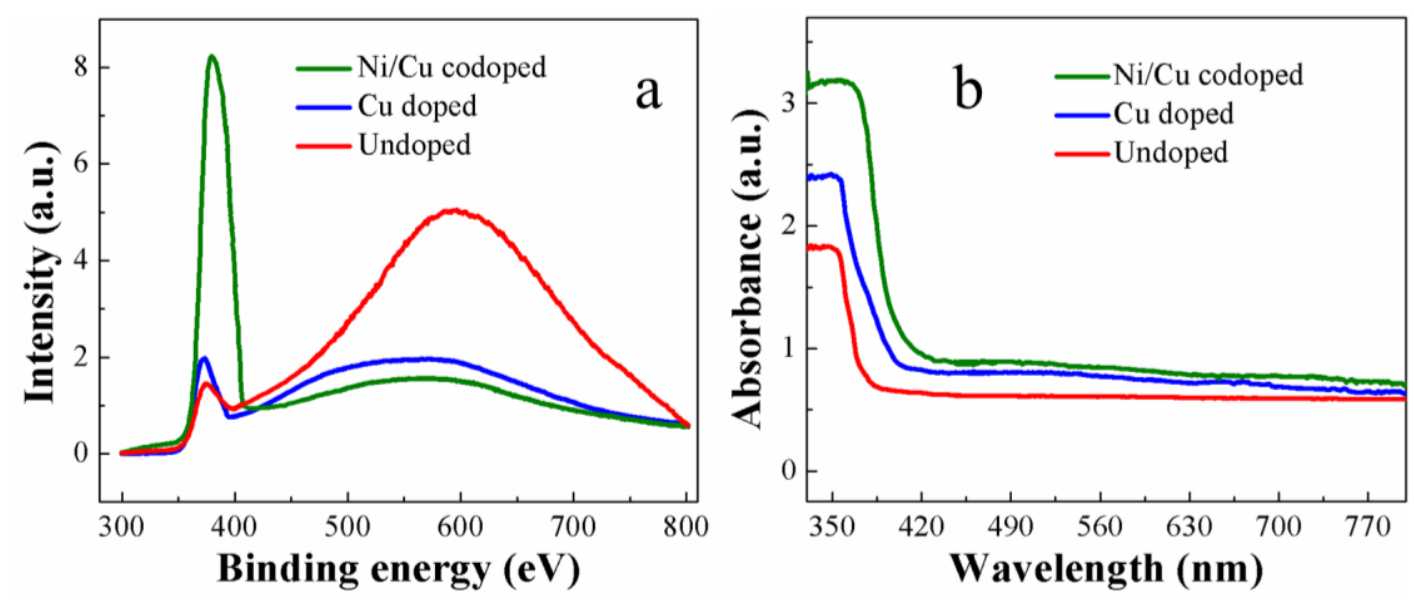

Figure 5. (a) Photoluminescence (PL) spectra and (b) ultraviolet (UV)/visible spectra of as-grown $\mathrm{ZnO}$ nanorods measured at room temperature.

The broadband spectra of visible emission in a range of $400-800 \mathrm{~nm}$ are to be attributed to a deep-level emission (DLE) caused by the recombination of photo-excited charges of many different types of intrinsic defects, such as oxygen vacancies and Zn interstitials, present in the nanocrystals. The precise nature of these defects corresponding with each DLE location is still a debatable subject [39-41]; however, the DLEs from the materials grown by hydrothermal method, especially at low process temperature, exist in general. This is because, during solution-based processes such as hydrothermal growth, a large amount of residual organic materials from the growth solution can penetrate into the crystal and produce deep-level defects which cannot be easily eradicated at low process temperature. External transition metal doping for the $\mathrm{ZnO}$ nanorod crystals is one efficient way to control the defect emissions as reported in many earlier studies [42-46]. In this study, the visible emissions were also greatly suppressed by 1.6 times after $\mathrm{Ni} / \mathrm{Cu}$ codoping compared to the emission from undoped sample as shown in Figure 5a. The intensity ratio between the NBE peak $\left(I_{U V}\right)$ and DLE peak $\left(I_{V I S}\right)$ can be employed to estimate the degree of intrinsic defect formation in the synthesized $\mathrm{ZnO}$ nanorod crystals. $I_{U V} / I_{V I S}$ ratios of our Ni/Cu codoped and $\mathrm{Cu}$ doped nanorods were $\sim 5.2$ and $\sim 1.1$, respectively, which are much higher than that $(\sim 0.3)$ of undoped $\mathrm{ZnO}$ sample.

Figure $5 \mathrm{~b}$ illustrates the optical absorption spectra of the $\mathrm{ZnO}$ nanorod crystals measured at room temperature using a UV-Visible spectrometer. As shown in the spectra, the absorption of $\mathrm{Cu}$ doped or $\mathrm{Ni} / \mathrm{Cu}$ codoped $\mathrm{ZnO}$ below cut-off wavelength was much higher than that measured from undoped $\mathrm{ZnO}$ nanorod crystals. The higher UV absorption in transition metal-doped $\mathrm{ZnO}$ nanorods could arise from a variety of reasons, such as the strain caused by doping and size effect of the nanorods [42]. In our case, the increases in the diameter of nanorod crystal and in the surface coverage of $\mathrm{ZnO}$ material on the surface by transition metal doping, as shown in the Figure 3, are supposed to be the main causes of the increase in absorption [23]. Another reason for the increase of absorption can be related with the existence of larger size of $\mathrm{ZnO}$ nanorods by $\mathrm{Cu} / \mathrm{Ni}$ codoping, resulting in much photon absorption in the way of Mie light scattering which is maximized when the scattering particles have a diameter similar to or larger than the wavelength of the incident light [43]. Furthermore, the shift in the band-edge of doped $\mathrm{ZnO}$ nanorods indicates the incorporation of $\mathrm{Cu}^{2+}$ and $\mathrm{Ni}^{2+}$ into $\mathrm{ZnO}$ host lattice. The considerable red shift in the absorption band-edge of $\mathrm{Ni} / \mathrm{Cu}$ codoped $\mathrm{ZnO}$ nanorods was observed due to the differences in $s p$ - $d$ exchange interactions between the localized $d$-electrons and the band electrons of $\mathrm{Ni}^{+2}$ [33]. 
Wide-scan spectra of XPS carried out in a binding energy (BE) of 0-1200 eV for all synthesized nanorod crystals are shown in Figure 6a. All vital constituents of $\mathrm{Zn}, \mathrm{O}$, and externally added impurities of $\mathrm{Cu}$ and $\mathrm{Ni}$ showed their corresponding photoemission peaks of various core-levels and spin-orbital splittings along with Auger peaks, and limited traces of carbon were also observed at $285 \mathrm{eV}$. Two explicit core-level Zn peaks in the XPS spectra were indicated as Zn-2p $3 / 2(1020.8 \mathrm{eV})$ and $\mathrm{Zn}-2 \mathrm{p}_{1 / 2}(1043.9 \mathrm{eV})$ separated by spin-orbital splitting [see Figure 6b]. Symmetric shapes of these photoemission peaks, peak locations, and spin orbital splitting value of $23.1 \mathrm{eV}$ of the $\mathrm{Zn}-2 \mathrm{p}$ doublet support the existence of the $\mathrm{Zn}^{2+}$ chemical state in the stoichiometry of $\mathrm{ZnO}$ in all cases of the samples. The Zn spectra measured from three different samples were almost similar to each other; therefore, the spectrum of undoped sample was shown in Figure $6 \mathrm{~b}$ as a representative example. However, the $\mathrm{Zn}-2 \mathrm{p}_{1 / 2}$ peak in $\mathrm{Ni} / \mathrm{Cu}$ codoped sample was shifted slightly toward higher $\mathrm{BE}$, which is associated with a higher state of oxidation of the $\mathrm{Zn}$ in $\mathrm{ZnO}$ matrix.
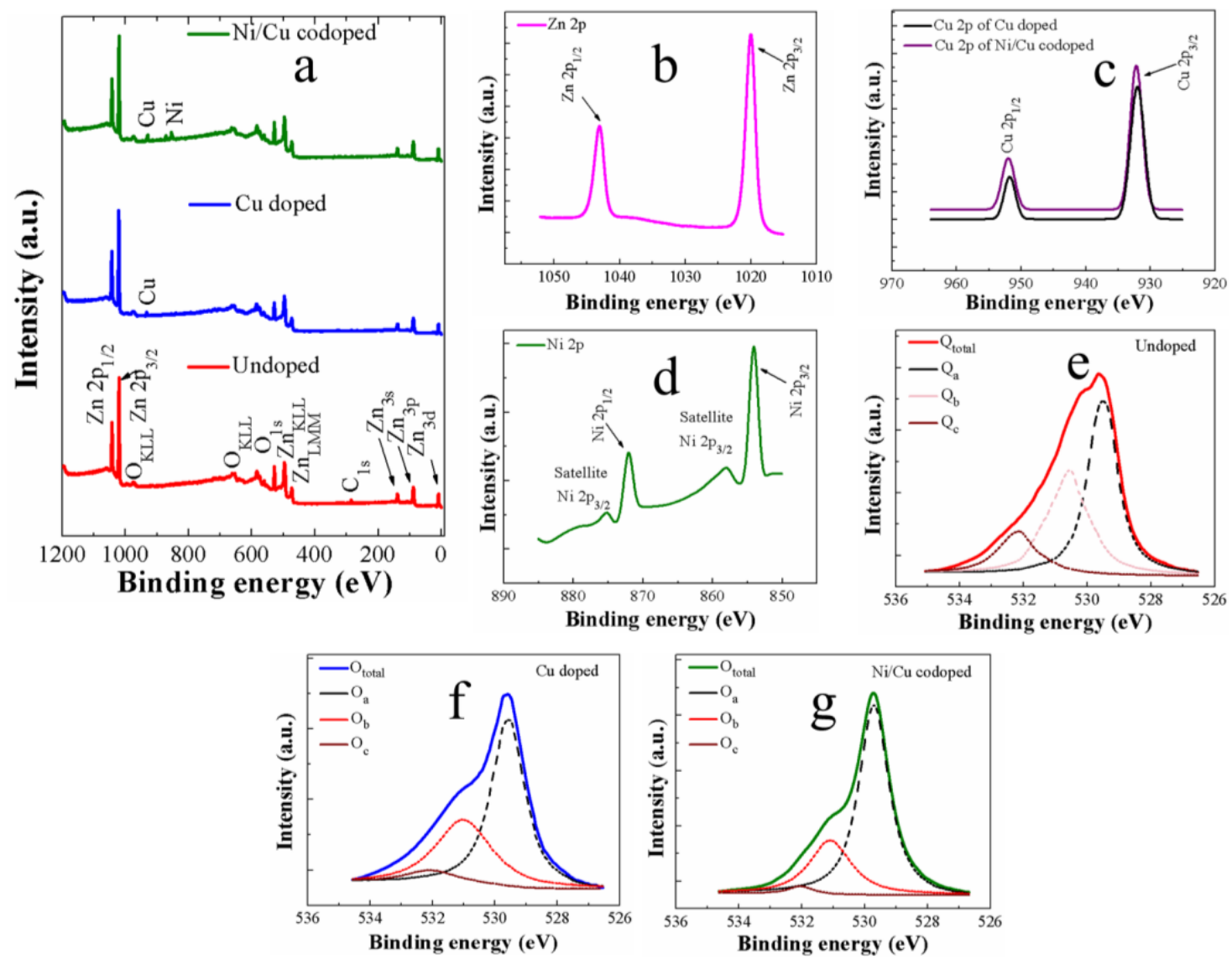

Figure 6. (a) Wide-scan X-ray photoelectron spectroscopy (XPS) spectra of the ZnO nanorods. High-resolution spectra of (b) Zn-2p (undoped), (c) Cu-2p (Cu doped and Ni/Cu codoped), and (d) $\mathrm{Ni}-2 \mathrm{p}$ (Ni/Cu codoped) core-levels measured from the $\mathrm{ZnO}$ nanorods. High-resolution O-1s core level spectra obtained from the $\mathrm{ZnO}$ nanorods prepared with (e) no doping, (f) $\mathrm{Cu}$ doping, and (g) Ni/Cu codoping are deconvoluted into three distant satellite peaks.

Figure $6 c, d$ illustrate clear core levels of $\mathrm{Cu}-2 \mathrm{p}$ and $\mathrm{Ni}-2 \mathrm{p}$, respectively, from the transition metal-doped samples. In the cases of $\mathrm{Cu}$ doped or $\mathrm{Ni} / \mathrm{Cu}$ codoped samples, a split of $\mathrm{Cu}-2 \mathrm{p}$ photoemission into $\mathrm{Cu}-2 \mathrm{p}_{3 / 2}(933.09 \mathrm{eV})$ and $\mathrm{Cu}-2 \mathrm{p}_{1 / 2}(953.1 \mathrm{eV})$ was clearly observed in the spectra. $\mathrm{Cu}$ is cationic in the $\mathrm{Cu}$ doped samples as reported in the literatures [44-46]. The oxidation state of $\mathrm{Cu}$ dopants in $\mathrm{ZnO}$ nanorod crystals results from most probably either $\mathrm{Cu}^{2+}, \mathrm{Cu}^{+}$, or both, and no other distinctive photoemission related to the secondary phase such as $\mathrm{CuO}_{2}$ was detected from the $\mathrm{Cu}$ doped samples. A slight shift $(\sim 0.2 \mathrm{eV})$ toward higher energy in core level spectra of $\mathrm{Cu}-2 \mathrm{p}$ of $\mathrm{Ni} / \mathrm{Cu}$ 
codoped nanorods (see Figure 6c) was shown, and this demonstrates that the occupation probability of $\mathrm{Cu}^{2+}$ valance state by $\mathrm{Cu}$ dopants is more dominant in $\mathrm{Ni} / \mathrm{Cu}$ codoped sample as the higher binding energy of $\mathrm{Cu}-2 \mathrm{p}$ spectra is closer to $\mathrm{Cu}^{2+}$ state. A core-level splitting of $\mathrm{Ni}-2 \mathrm{p}_{3 / 2}$ and $\mathrm{Ni}-2 \mathrm{p}_{1 / 2}$ was also detected at 854.1 and $872.2 \mathrm{eV}$, respectively, with two corresponding satellite peaks at 857.5 and 875.7 $\mathrm{eV}$. Two prominent $\mathrm{Ni}$ peaks observed in the $\mathrm{Ni} / \mathrm{Cu}$ codoped samples were adjacent to that of the $\mathrm{Ni}^{2+}$ ions [47], and they confirm the presence of $\mathrm{Ni}^{2+}$ ions in the host lattice of $\mathrm{ZnO}$. The satellite peaks are also observed due to the trivalent $\mathrm{Ni}^{3+}$ cations.

By investigating the asymmetric O-1s peaks in depth, it is possible to grasp the detailed information for the contribution of oxygen bindings in the $\mathrm{ZnO}$ crystals. We deconvoluted the O-1s peak into three satellite individual peaks of $\mathrm{O}_{a}, \mathrm{O}_{b}$, and $\mathrm{O}_{c}$ as shown in Figure 6e-g. Among them, a peak at the lowest $\mathrm{BE}(\sim 529.7 \pm 0.2 \mathrm{eV})$, symbolized as $\mathrm{O}_{\mathrm{a}}$, is known to originate from the $\mathrm{O}^{2-}$ ions establishing bonds with the metal ions $\left(\mathrm{Zn}^{2+}, \mathrm{Cu}^{2+}, \mathrm{Ni}^{2+}\right)$ in the wurtzite structure of $\mathrm{ZnO}$. Since $\mathrm{O}_{\mathrm{a}}$ is an excellent measure of stoichiometric oxygen existence in the $\mathrm{ZnO}$ crystals, we estimated the stoichiometry of each synthesized nanorod sample by estimating $S \mathrm{O}_{\mathrm{a}} / S Z \mathrm{n}$, where $S \mathrm{O}_{\mathrm{a}}$ and $S Z n$ respectively represent the peak curve integration of $\mathrm{O}_{a}$ and $\mathrm{Zn}$ in the spectra. It was clearly shown in Table 2 that the percentage contribution of $\mathrm{O}_{a}$ in $\mathrm{O}_{\text {total }}\left(\mathrm{O}_{\text {total }}=\mathrm{O}_{\mathrm{a}}+\mathrm{O}_{\mathrm{b}}+\mathrm{O}_{\mathrm{c}}\right)$ shows the maximum in the case of Ni/Cu codoped $\mathrm{ZnO}$ nanorods. Each percentage value of $\mathrm{O}_{\mathrm{a}}, \mathrm{O}_{\mathrm{b}}$, and $\mathrm{O}_{\mathrm{c}}$ listed in Table 2 was estimated by $S \mathrm{O}_{\mathrm{x}} /$ $S \mathrm{O}_{\text {total, }}$, where $S \mathrm{O}_{\mathrm{x}}$ can be obtained by curve integration of the O-1s peak $(x=\mathrm{a}, \mathrm{b}, \mathrm{c})$, and $S \mathrm{O}_{\text {total }}$ is the summation of curve integrations for each O-1s satellite peak. Even though our ZnO crystals are oxygen deficient in nature, the atomic ratio of $\mathrm{O}_{a} / \mathrm{Zn}$ was significantly improved by transition metal doping, and the highest value of 0.78 was shown from the $\mathrm{Ni} / \mathrm{Cu}$ codoped sample. This increase in $\mathrm{O}_{\mathrm{a}}$ contribution can be attributed to the stronger bonding characteristics of metal-oxygen in $\mathrm{Cu}$ doped and $\mathrm{Ni} / \mathrm{Cu}$ codoped nanorods because the electronegativity $(\chi)$ of $\mathrm{Ni}(\chi=1.91)$ and $\mathrm{Cu}(\chi=1.90)$ are higher than that of $\mathrm{Zn}(\chi=1.65)[48,49]$. The medium BE component of $\mathrm{O}_{\mathrm{b}}(\sim 531 \pm 0.2 \mathrm{eV})$ is known to emerge from $\mathrm{O}^{2-}$ ions in the oxygen-deficient regions (where oxygen vacancies are present) of the $\mathrm{ZnO}$ matrix. The $\mathrm{O}_{\mathrm{c}}$ component of higher $\mathrm{BE}(\sim 532 \pm 0.09 \mathrm{eV})$ is principally associated with chemisorbed oxygen or $-\mathrm{OH}$ species on the surface of $\mathrm{ZnO}$ nanocrystals during the growth of nanorods in organic solutions [50,51]. As summarized in Table 2, the presence of $\mathrm{O}_{\mathrm{c}}$-related defects was at a minimum in transition metal-doped nanorods. Another reason why $\mathrm{O}_{c}$ contribution is higher in the case of undoped $\mathrm{ZnO}$ sample can be a higher surface-to-volume with longer average length and smaller average diameter of the nanorod crystals [52].

Table 2. Atomic percentage values of $\mathrm{Cu}$ and $\mathrm{Ni}$, percentage values of individual O-1s satellite peaks, and $\mathrm{O} / \mathrm{Zn}$ atomic ratios of the nanorod crystals estimated by XPS deconvolution analysis.

\begin{tabular}{ccccccc}
\hline Sample & Cu at \% & Ni at \% & Oa (\%) & Ob (\%) & Oc (\%) & O/Zn Ratio \\
\hline Undoped & 0 & 0 & 47.74 & 38.31 & 13.11 & 0.63 \\
Cu doped & 0.58 & 0 & 56.81 & 32.79 & 9.98 & 0.71 \\
Ni/Cu codoped & 0.47 & 0.26 & 62.13 & 30.73 & 8.87 & 0.78 \\
\hline
\end{tabular}

Based on the findings of our material characterizations, we fabricated UV-PDs of IDE patterns on the PET substrates. Current-voltage (I-V) characteristics, transient time response, and spectral responsivity were measured from the PDs. We carried out the photo-response characterizations of our flexible PDs using a $300 \mathrm{~W}$ wide-band (200-800 nm) Xenon lamp (model 300XF-R1) as an input light source. The source light was filtered into a single wavelength of $350 \mathrm{~nm}$ using a monochromator (CM11 1/4 m) with a grating of 2400 lines-per-mm. The output light from the monochromatic source was directed onto the surface of the samples, and the PD samples were probed using a Keithley source measurement unit with two-input probe station. The on/off of the input UV light for transient measurement was controlled by a programmable electronic shutter (model 71,445). The whole measurement setup was housed in a black box to prevent any influence of ambient light. 
The UV sensing mechanism of photoconductive PDs based on $\mathrm{ZnO}$ nanorods is associated with the chemisorption of atmospheric oxygen at the surface of $\mathrm{ZnO}$ nanorods grown on IDE structure [53]. As-grown $\mathrm{ZnO}$ nanorods are $n$-type in nature because of various intrinsic defects, such as oxygen vacancies [10,54]. In the dark condition, oxygen molecules from the atmosphere tend to trap the free electrons present in the conduction band of $n$-type $\mathrm{ZnO}$ nanorods [55] and get adsorbed at the surface of the nanorods by $\left[\mathrm{O}_{2}+e^{-} \rightarrow \mathrm{O}_{2}^{-}\right.$adsorbed $]$, as illustrated in Figure 7. Consequently, the electron concentration at the surface of nanorod is reduced with the expansion of low conductivity surface depletion layer.

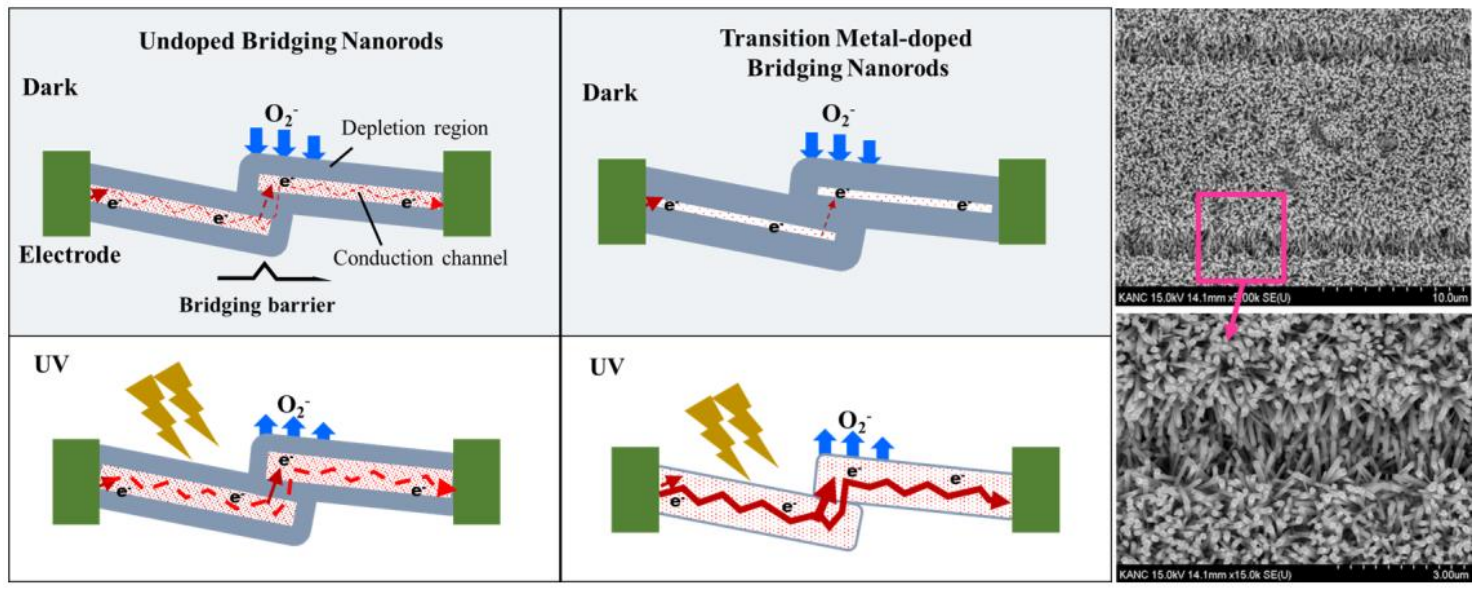

Figure 7. Left: Schematic illustrations of the carrier generation and transport processes in the bridging $\mathrm{ZnO}$ nanorods (undoped and transition metal-doped). Right: SEM images of bridging ZnO nanorods grown on the PET substrates fabricated with Au IDE pattern.

When $\mathrm{Cu}$ and/or Ni dopants are introduced, they tend to drop the free electron concentration, $n$, in the conduction band because of the reduced oxygen vacancies in the $\mathrm{ZnO}$ nanorod crystal as shown in our results of PL and XPS analysis and also in the report of $R$. Shabannia [24]. The surface depletion layer thickness, $\delta$ of the nanorods is given by [9]:

$$
\begin{aligned}
& \delta=L_{D}\left(\frac{e V_{s}}{k T}\right)^{1 / 2} \\
& L_{D}=\left(\frac{\varepsilon_{0} k T}{e^{2} n}\right)^{1 / 2}
\end{aligned}
$$

where $L_{D}$ is the Debye length, $V_{\mathrm{S}}$ is the adsorbate-induced band bending, $e$ is the electron charge, $k T$ is the thermal energy, and $\varepsilon_{o}$ is the permittivity. The surface depletion layer of the transition metal-doped $\mathrm{ZnO}$ nanorod will then grow thicker than that of undoped one. The conduction channels in our IDE PDs include nanorod-nanorod junctions. Electrons must overcome the bridging barrier to transport from one nanorod to another as shown in the left of Figure 7. These barriers are formed by the surface depletion layers. The channel conductance, $G$, of the bridging $\mathrm{ZnO}$ nanorods is influenced by not only $n$ but also dimension of the conduction channel formed inside the nanorods, and this relationship [9] can be expressed by:

$$
G=n e \mu \pi(D-2 \delta) / 4
$$

where $\mu$ is the electron mobility, $D$ represents the diameter of the nanorod, and $l$ is the length between the two electrodes. However, more than this dimensional effect of conduction channel, the surface depletion regions in each nanorod act as barriers preventing the electron transfer through the nanorod-nanorod bridge since the current has to flow through this bridging barriers of connected nanorods. Therefore, when the diameters of the nanorods exceed the Debye length, such as in our 
case, the dominant bottleneck of charge transport in our PDs will be the nanorod-nanorod junction. Figure 8 a shows the lowest dark current, $I_{\text {dark }}$, of $\sim 3.1 \mu \mathrm{A}$ (at $2 \mathrm{~V}$ ) in the case of the PDs with Ni/Cu codoped nanorods. On the other hand, much higher $I_{\text {dark }}$ of $\sim 17.2$ and $\sim 25 \mu \mathrm{A}$ were measured at $2 \mathrm{~V}$ from the PDs with $\mathrm{Cu}$ doped and undoped nanorods, respectively. The lowest $I_{\text {dark }}$ measured from the PDs with Ni/Cu codoped nanorods of the largest nanorods diameter supports our premise that the charge transfer in our PDs is controlled by the surface depletion layer at the nanorod-nanorod bridge.
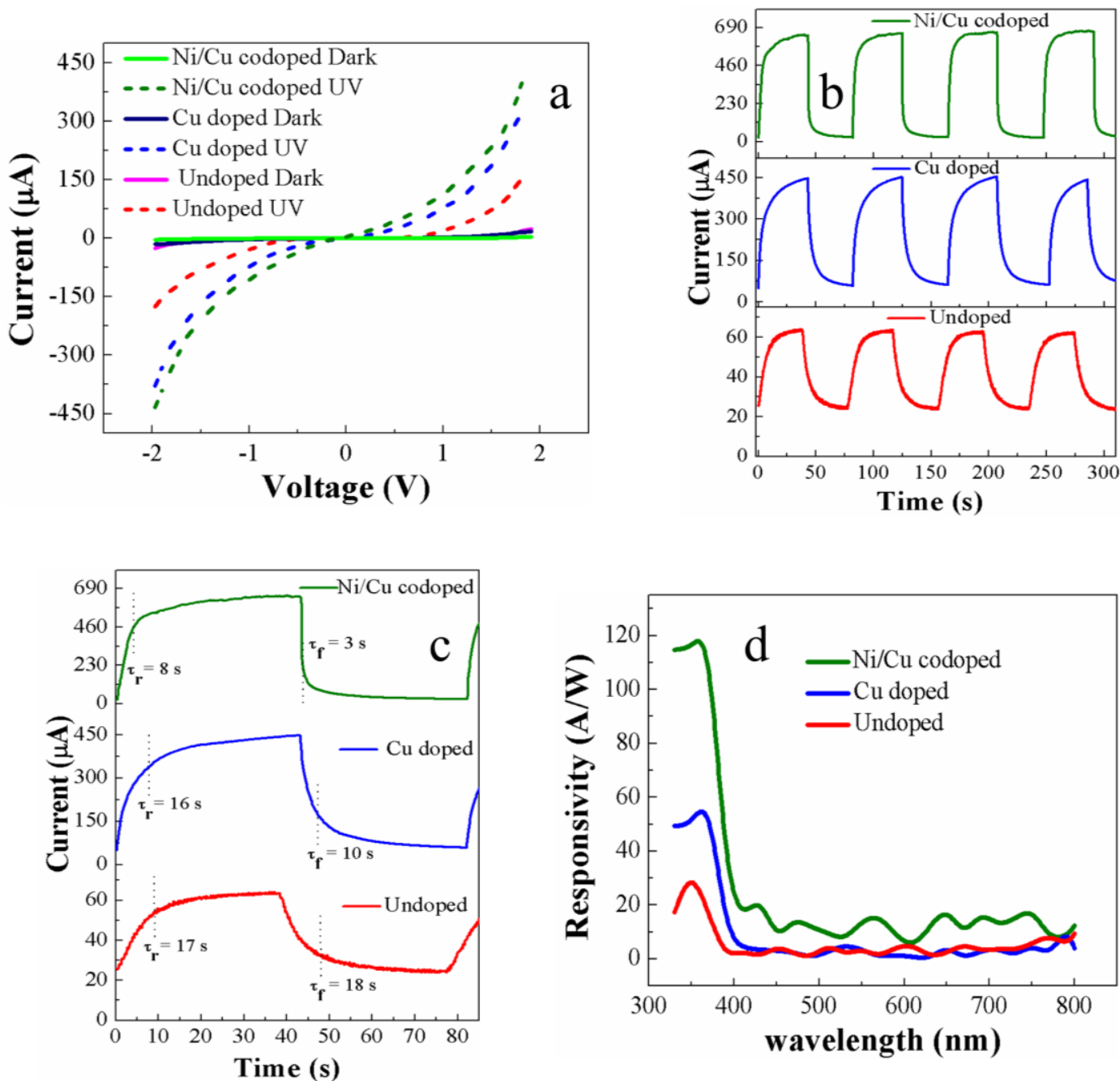

Figure 8. (a) Current-voltage (I-V) characteristics, (b) photo-response transient characteristics, (c) magnified views of single-cycle transient, and (d) spectral responsivities of PDs with undoped, $\mathrm{Cu}$ doped, and $\mathrm{Ni} / \mathrm{Cu}$ codoped $\mathrm{ZnO}$ nanorods.

Electron-hole pairs are generated by optical absorption under UV light illumination, and the generated holes recombine with the electrons trapped by the oxygen adsorbed [18]. This leads to a desorption process of the $\mathrm{O}_{2}$ molecules by $\left[\mathrm{O}_{2}^{-}\right.$adsorbed $\left.+h \stackrel{h v}{\rightarrow} \mathrm{O}_{2}\right]$ (see Figure 7). At the same time, the surface depletion region will keep shrinking if holes can be continuously supplied to the surface. Photocurrent, $I_{U V}$ (at $2 \mathrm{~V}$ ), measured from the PDs with Ni/Cu codoped, Cu doped, and undoped nanorods were $\sim 402, \sim 320$, and $\sim 153 \mu \mathrm{A}$, respectively, are shown in Figure 8a. Trapping of carriers under dark and detrapping them under illumination by the defect states can be responsible for higher $I_{U V}$ in PDs with hydrothermally grown transition metal-doped $\mathrm{ZnO}$ nanorods than that with undoped nanorods as claimed by S. Sarkar et al. [56]. According to their interpretation, the photo-excited carriers can rapidly recombine through many deep-level defects present in hydrothermally grown $\mathrm{ZnO}$ nanorods. However, it was also found that the introduction of transition metal dopants can 
significantly reduce the deep-level defects, thereby eventually minimizing the loss of photo-excited carriers with a remarkable increase in photocurrent. It was also reported by West et al. [57] that the $\mathrm{Cu}$ doping in $\mathrm{ZnO}$ forms neutral complexes that can be ionized by a photon of energy greater than $1.45 \mathrm{eV}$. This result also supports that the photo-excited electron concentration in the conduction band of the transition metal-doped samples is higher than that in undoped samples.

Another possible cause for enhanced photocurrent in transition metal-doped PDs is the minimized thickness of bridging barrier as illustrated in Figure 7. When $\mathrm{Cu}$ and/or $\mathrm{Ni}$ are doped into $\mathrm{ZnO}$ nanorods, as many photo-excited holes as possible are freed from the recombination or trapping by deep-level defects, thus continuously shrinking the surface depletion layer on the nanorod surface. Assuming that the tunnel current is an exponential function of the bridging barrier thickness, the current will be very sensitive to small change in the barrier. A great increase of the UV-to-dark current ratio $\left(I_{U V} / I_{\text {dark }}\right)$ up to $\sim 130$ was obtained from the PDs with $\mathrm{Ni} / \mathrm{Cu}$ codoped nanorods at $2 \mathrm{~V}$, while a much lower $I_{U V} / I_{\text {dark }}$ of $\sim 6$ was measured from the PDs with undoped nanorods.

One vital performance parameter for the PDs is the real-time transient response to estimate the rise-up (response) time and fall-down (recovery) time under UV illumination (at $350 \mathrm{~nm}$ ) on and off, which are defined as time intervals for the $I_{U V}$ to rise up to $90 \%$ of maximum saturation value under UV turn-on and for the $I_{U V}$ to fall off by $90 \%$ from maximum value under UV turn-off, respectively. Overall transient speed of our UV PDs depends upon the process of adsorption or desorption kinetics of $\mathrm{O}_{2}$ on the $\mathrm{ZnO}$ nanorod surface; therefore, this surface kinetics is governed by the density of the defects near the surface as well as the partial pressure of atmospheric oxygen [56]. First, the improvement in response time of our PDs is deeply associated with the desorption kinetics of $\mathrm{O}_{2}$. The incorporation of $\mathrm{Cu}$ and/or $\mathrm{Ni}$ in $\mathrm{ZnO}$ nanorods increases the photo-generated holes, which move toward the surface and facilitate the neutralization of the ionized $\mathrm{O}_{2}$ molecules, due to significant reduction in the concentration of traps near the surface, thereby leading to a faster desorption from the $\mathrm{ZnO}$ surface. The response times measured from the PDs with $\mathrm{Ni} / \mathrm{Cu}$ codoped and $\mathrm{Cu}$ doped nanorods were $\sim 8$ and $\sim 16 \mathrm{~s}$, respectively, which are far less than those $(\sim 17 \mathrm{~s})$ from the PDs with undoped nanorods, as shown in Figure 8b,c. Due to the reduction in deep level defects and the shrinking of depletion layer in $\mathrm{Cu}$ or $\mathrm{Ni} / \mathrm{Cu}$ doped nanorods, the transport rate of photo-generated holes toward the surface of $\mathrm{ZnO}$ nanorods can improve with the rise time which is associated with effective desorption of $\mathrm{O}_{2}$. In the case of PDs with undoped nanorods, the photo-generated charge carriers fill the traps first and photocurrent reaches a maximum (saturation) after all of the traps are filled which causes a delay in reaching the maximum photocurrent [58]. On the other hand, the improvement in recovery process of $\mathrm{Cu}$ or Ni/Cu doped nanorods is directly associated with $\mathrm{O}_{2}$ adsorption. The deep-level defects on the surface of transition metal-doped nanorods are considerably reduced, and this results in lowering the surface band bending, thereby increasing the diffusional flux of electrons toward the surface of nanorods to produce adsorbed $\mathrm{O}_{2}{ }^{-}$ions with the reduction of electron energy barrier [50].

Another important figure of merit to evaluate the PD performance is spectral responsivity $\boldsymbol{R}$ defined as follows [59].

$$
R=\frac{I_{U V}-I_{\text {dark }}}{P_{\text {in }}}
$$

where $P_{\text {in }}$ represents the power of incident light on the active area of the fabricated device. Figure $9 \mathrm{~d}$ shows the measured spectral responses of IDE-based UV-PDs with an effective device area of $0.238 \mathrm{~mm}^{2}$ at a bias voltage of $2 \mathrm{~V}$ under a light intensity of $140 \mu \mathrm{W} / \mathrm{cm}^{2}$. The PDs with Ni/Cu codoped nanorods showed a very high $\boldsymbol{R}$ of $\sim 123 \mathrm{~A} / \mathrm{W}$ at $370 \mathrm{~nm}$. This high $\boldsymbol{R}$ value is mainly due to an excellent quantum efficiency of the PDs, and it arises from the fact that most of the electron-hole pairs generated during UV irradiation are collected into photocurrent with the minimized recombination taking place by defect levels in the high crystalline-quality doped nanorods. Another reason for the increase of $\boldsymbol{R}$ is the enhanced absorption related with the existence of larger size of $\mathrm{ZnO}$ nanorods by $\mathrm{Cu} / \mathrm{Ni}$ codoping by Mie light scattering as discussed earlier. In conclusion, the $\boldsymbol{R}$ value measured from the PDs with $\mathrm{Ni} / \mathrm{Cu}$ 
codoped nanorods is the best performance among the recently investigated UV sensors $[60,61]$ based on $\mathrm{ZnO}$ nanostructures hydrothermally grown on flexible substrates.
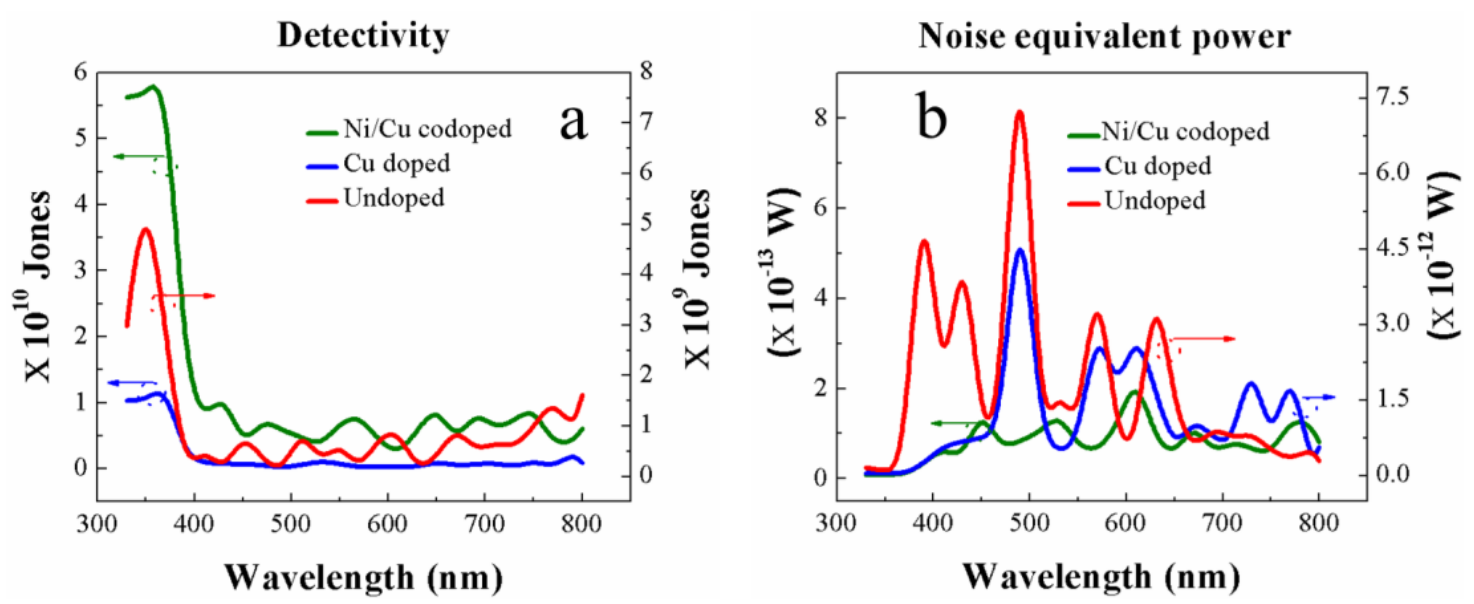

Figure 9. (a) Specific detectivity and (b) noise equivalent power as functions of radiant light wavelength.

The performance of our PDs was also evaluated by specific detectivity, $D^{*}$, and noise equivalent power, NEP, normalized per square root of the device area which is equal to the reciprocal of detectivity. NEP is defined as the signal power that gives a signal-to-noise ratio of one in a one hertz output bandwidth. Therefore, this value is a measure of the weakest optical signal that can be detected, and it is desirable to have a NEP as low as possible. $D *$ is defined as follows [62]

$$
D^{*}=\sqrt{A} \mathrm{R} / \sqrt{2 q I_{\text {dark }}}
$$

where $A$ represents the active device area and $q$ is the charge of an electron. $D^{*}$ versus wavelength estimated at a bias voltage of $2 \mathrm{~V}$ and a light intensity of $140 \mathrm{~mW} / \mathrm{cm}^{2}$ of our IDE-based UV-PDs are shown in Figure 9a. The highest $D^{*}$ of $\sim 6 \times 10^{10}$ Jones $\left(\mathrm{cm} \mathrm{Hz}^{1 / 2} / \mathrm{W}\right)$ was obtained at $370 \mathrm{~nm}$ from the devices with $\mathrm{Ni} / \mathrm{Cu}$ codoped $\mathrm{ZnO}$ nanorods. Despite that our PDs were fabricated at a very low temperature $-150{ }^{\circ} \mathrm{C}$ to accommodate the thermally unstable plastic substrates, the measured detectivity was quite high and even comparable with those measured from the devices of Ni doped $\mathrm{ZnO}$ nanoparticles on glass $\left(\sim 3.7 \times 10^{10}\right.$ Jones) [28] and Mn-doped $\mathrm{ZnO}$ films on quartz $\left(\sim 1.6 \times 10^{10}\right.$ Jones) [63] prepared at much higher process temperatures. Figure $9 b$ shows the NEPs of the fabricated PDs, and a very low noise power of $\sim 8 \times 10^{-15} \mathrm{~W}$ was measured at $370 \mathrm{~nm}$ from the devices with $\mathrm{Ni} / \mathrm{Cu}$ codoped $\mathrm{ZnO}$ nanorods.

\section{Conclusions}

We performed a comparative study on the performance of the IDE structure-based UV PDs fabricated on PET substrates with $\mathrm{ZnO}$ nanorods doped by $\mathrm{Cu}$ or $\mathrm{Ni} / \mathrm{Cu}$ with the devices prepared with undoped nanorods. In conclusion, the UV-PDs based on Ni/Cu codoped nanorods exhibited significantly improved device performance in terms of spectral responsivity of ( 123 A/W), on-off current ratio of $(\sim 130)$, and current rise and fall times $(\sim 8$ and $\sim 3 \mathrm{~s})$ in transient response compared to those of devices fabricated by using undoped or $\mathrm{Cu}$-only doped nanorods. As shown in our surface characterizations of SEM, XPS, PL and XRD, this improvement is due to the evolutionary change in morphology and crystalline quality of the nanorod crystals grown through $\mathrm{Ni} / \mathrm{Cu}$ codoping with the enhancement in $\mathrm{O} / \mathrm{Zn}$ stoichiometry, (002) preferred orientation, and the reduction of visible emission defects. This doping technique using a low-temperature $\mathrm{ZnO}$ nanorod synthesis method is expected to be used to improve the performance of PDs manufactured on flexible plastic substrates which can be an inevitable solution in the future because of their unique benefits such as high resistance to impact damage, transparency, transportability, and low cost. 
Author Contributions: The research study was carried out in collaboration of the aforementioned authors and supervised by S.-D.K., H.M.S.A. comprehended the idea and planned the experiments. F.K. assisted in draft preparation. N.U.H. helped in data analysis. K.N., H.Y.K., S.L., T.-H.E. helped in carrying out the experiments. H.M.S.A. wrote the manuscript which was edited by S.-D.K. Resource allocation and funding acquisition were done by S.-D.K.

Funding: This research received the external funding and the details of funding sources are mentioned in the acknowledgments section.

Acknowledgments: This work was supported by the National Research Foundation (NRF) of Korea grant funded through the Ministry of Science and Information and communication technology (ICT), Korea (Project No. 2019R1H1A2079881). Material characterization was supported by Nano-material Technology Development Program through the NRF funded by the Ministry of Science, ICT and Future Planning (2009-0082580).

Conflicts of Interest: The authors declare no conflicts of interest.

\section{References}

1. Chortos, A.; Liu, J.; Bao, Z. Pursuing prosthetic electronic skin. Nat. Mater. 2016, 15, 937-950. [CrossRef]

2. Zhang, B.; Korolj, A.; Lai, B.F.L.; Radisic, M. Advances in organ-on-a-chip engineering. Nat. Rev. Mater. 2018, 3, 257-278. [CrossRef]

3. Bigio, I.J.; Mourant, J.R. Ultraviolet and visible spectroscopies for tissue diagnostics: fluorescence spectroscopy and elastic-scattering spectroscopy. Phys. Med. Biol. 1997, 42, 803-814. [CrossRef]

4. Zhou, Z.; Zhao, Y.; Cai, Z. Low-temperature growth of ZnO nanorods on PET fabrics with two-step hydrothermal method. Appl. Surf. Sci. 2010, 256, 4724-4728. [CrossRef]

5. Dang, V.Q.; Trung, T.Q.; Duy, L.T.; Kim, B.Y.; Siddiqui, S.; Lee, W.; Lee, N.E. High-Performance Flexible Ultraviolet (UV) Phototransistor Using Hybrid Channel of Vertical ZnO Nanorods and Graphene. ACS Appl. Mater. Interfaces 2015, 7, 11032-11040. [CrossRef]

6. Rong, P.; Ren, S.; Yu, Q. Fabrications and Applications of ZnO Nanomaterials in Flexible Functional Devices-A Review. Crit. Rev. Anal. Chem. 2018, 8347. [CrossRef]

7. Chaudhary, S.; Umar, A.; Bhasin, K.K.; Baskoutas, S. Chemical sensing applications of ZnO nanomaterials. Materials (Basel) 2018, 11, 1-38. [CrossRef]

8. Zhai, T.; Fang, X.; Liao, M.; Xu, X.; Zeng, H.; Yoshio, B.; Golberg, D. A comprehensive review of one-dimensional metal-oxide nanostructure photodetectors. Sensors 2009, 9, 6504-6529. [CrossRef]

9. Alenezi, M.R.; Henley, S.J.; Silva, S.R.P. On-chip fabrication of high performance nanostructured ZnO UV detectors. Sci. Rep. 2015, 5, 8516. [CrossRef]

10. Kouklin, N. Cu-Doped ZnO Nanowires for Efficient and Multispectral Photodetection Applications. Adv. Mater. 2008, 20, 2190-2194. [CrossRef]

11. Lupan, O.; Chai, G.; Chow, L.; Emelchenko, G.A.; Heinrich, H.; Ursaki, V.V.; Gruzintsev, A.N.; Tiginyanu, I.M.; Redkin, A.N. Ultraviolet photoconductive sensor based on single ZnO nanowire. Phys. Status Solidi Appl. Mater. Sci. 2010, 207, 1735-1740. [CrossRef]

12. Jin, B.J.; Im, S.; Lee, S.Y. Violet and UV luminescence emitted from $\mathrm{ZnO}$ thin films grown on sapphire by pulsed laser deposition. Thin Solid Films 2000, 366, 107-110. [CrossRef]

13. Heo, Y.W.; Varadarajan, V.; Kaufman, M.; Kim, K.; Norton, D.P.; Ren, F.; Fleming, P.H. Site-specific growth of Zno nanorods using catalysis-driven molecular-beam epitaxy. Appl. Phys. Lett. 2002, 81, 3046-3048. [CrossRef]

14. Park, W.L.; Yi, G.C.; Kim, M.; Pennycook, S.J. ZnO nanoneedles grown vertically on Si substrates by non-catalytic vapor-phase epitaxy. Adv. Mater. 2002, 14, 1841-1843. [CrossRef]

15. Vayssieres, L. Growth of arrayed nanorods and nanowires of $\mathrm{ZnO}$ from aqueous solutions. Adv. Mater. 2003, 15, 464-466. [CrossRef]

16. Ali, H.S.; Alghamdi, A.; Murtaza, G.; Arif, H.S.; Naeem, W.; Farid, G.; Sharif, S.; Ashiq, M.; Shabbir, S. Facile Microemulsion Synthesis of Vanadium-Doped ZnO Nanoparticles to Analyze the Compositional, Optical, and Electronic Properties. Materials (Basel) 2019, 12, 821. [CrossRef]

17. Habba, Y.; Capochichi-Gnambodoe, M.; Leprince-Wang, Y. Enhanced Photocatalytic Activity of Iron-Doped ZnO Nanowires for Water Purification. Appl. Sci. 2017, 7, 1185. [CrossRef]

18. Janotti, A.; Van de Walle, C.G. Fundamentals of zinc oxide as a semiconductor. Rep. Prog. Phys. 2009, 72, 126501. [CrossRef] 
19. Xu, J.; Liu, P.; Shi, S.; Zhang, X.; Wang, L.; Ren, Z.; Ge, L.; Li, L. Effect of Cu ions on the morphology, structure and luminescence properties of $\mathrm{ZnO}$ nanorod arrays prepared by hydrothermal method. Appl. Surf. Sci. 2012, 258, 7118-7125. [CrossRef]

20. Ahmed, S.A. Structural, optical, and magnetic properties of Mn-doped ZnO samples. Results Phys. 2017, 7, 604-610. [CrossRef]

21. Samanta, A.; Goswami, M.N.; Mahapatra, P.K. Magnetic and electric properties of Ni-doped ZnO nanoparticles exhibit diluted magnetic semiconductor in nature. J. Alloys Compd. 2018, 730, 399-407. [CrossRef]

22. Yao, I.C.; Tseng, T.Y.; Lin, P. ZnO nanorods grown on polymer substrates as UV photodetectors. Sensors Actuators, A Phys. 2012, 178, 26-31. [CrossRef]

23. Li, X.; Chen, X.; Yi, Z.; Zhou, Z.; Tang, Y.; Yi, Y. Fabriction of ZnO Nanorods with Strong UV Absorption and Different Hydrophobicity on Foamed Nickel under Different Hydrothermal Conditions. Micromachines 2019, 10, 164. [CrossRef]

24. Shabannia, R. Synthesis and characterization of $\mathrm{Cu}$-doped $\mathrm{ZnO}$ nanorods chemically grown on flexible substrate. J. Mol. Struct. 2016, 1118, 157-160. [CrossRef]

25. Ben Elkamel, I.; Hamdaoui, N.; Mezni, A.; Ajjel, R.; Beji, L. High responsivity and 1/: F noise of an ultraviolet photodetector based on Ni doped ZnO nanoparticles. RSC Adv. 2018, 8, 32333-32343. [CrossRef]

26. Chow, L.; Lupan, O.; Chai, G.; Khallaf, H.; Ono, L.K.; Roldan Cuenya, B.; Tiginyanu, I.M.; Ursaki, V.V.; Sontea, V.; Schulte, A. Synthesis and characterization of Cu-doped $\mathrm{ZnO}$ one-dimensional structures for miniaturized sensor applications with faster response. Sensors Actuators, A Phys. 2013, 189, 399-408. [CrossRef]

27. Kim, K.H.; Yoshihara, Y.; Abe, Y.; Kawamura, M.; Kiba, T.; Endo, T. Effects of Ni dopant on structural properties of zinc oxide nanorods. Microelectron. Eng. 2016, 165, 20-22. [CrossRef]

28. Rooydell, R.; Brahma, S.; Wang, R.C.; Modaberi, M.R.; Ebrahimzadeh, F.; Liu, C.P. Cu doped ZnO nanorods with controllable $\mathrm{Cu}$ content by using single metal organic precursors and their photocatalytic and luminescence properties. J. Alloys Compd. 2017, 691, 936-945. [CrossRef]

29. Singh, P.; Kumar, A.; Deepak; Kaur, D. Growth and characterization of ZnO nanocrystalline thin films and nanopowder via low-cost ultrasonic spray pyrolysis. J. Cryst. Growth 2007, 306, 303-310. [CrossRef]

30. Khan, W.; Khan, F.; Ajmal, H.; Huda, N.; Kim, J.; Kim, S.-D. Evolution of Structural and Optical Properties of ZnO Nanorods Grown on Vacuum Annealed Seed Crystallites. Nanomaterials 2018, 8, 68. [CrossRef]

31. Gómez-Pozos, H.; Arredondo, E.; Maldonado Álvarez, A.; Biswal, R.; Kudriavtsev, Y.; Pérez, J.; Casallas-Moreno, Y.; Olvera Amador, M. Cu-Doped ZnO Thin Films Deposited by a Sol-Gel Process Using Two Copper Precursors: Gas-Sensing Performance in a Propane Atmosphere. Materials (Basel) 2016, 9 , 87. [CrossRef]

32. Babikier, M.; Wang, D.; Wang, J.; Li, Q.; Sun, J.; Yan, Y.; Yu, Q.; Jiao, S. Cu-doped ZnO nanorod arrays: The effects of copper precursor and concentration. Nanoscale Res. Lett. 2014, 9, 1-9. [CrossRef]

33. Theyvaraju, D.; Muthukumaran, S. Preparation, structural, photoluminescence and magnetic studies of $\mathrm{Cu}$ doped ZnO nanoparticles co-doped with Ni by sol-gel method. Phys. E Low-dimensional Syst. Nanostructures 2015, 74, 93-100. [CrossRef]

34. Lupan, O.; Chow, L.; Chai, G.; Schulte, A.; Park, S.; Heinrich, H. A rapid hydrothermal synthesis of rutile SnO2 nanowires. Mater. Sci. Eng. B Solid-State Mater. Adv. Technol. 2009, 157, 101-104. [CrossRef]

35. Gupta, R.K.; Ghosh, K.; Patel, R.; Kahol, P.K. Wide bandgap Mg-doped ZnAlO thin films for optoelectronic applications. Mater. Sci. Eng. B Solid-State Mater. Adv. Technol. 2009, 156, 1-5. [CrossRef]

36. Sharma, S.K.; Kaur, N.; Lee, B.; Kim, C.; Lee, S.; Kim, D.Y. Diameter and density controlled growth of yttrium functionalized zinc oxide (YZO) nanorod arrays by hydrothermal. Curr. Appl. Phys. 2015, 15, S82-S88. [CrossRef]

37. Hang, D.R.; Islam, S.E.; Sharma, K.H.; Kuo, S.W.; Zhang, C.Z.; Wang, J.J. Annealing effects on the optical and morphological properties of $\mathrm{ZnO}$ nanorods on $\mathrm{AZO}$ substrate by using aqueous solution method at low temperature. Nanoscale Res. Lett. 2014, 9, 1-7. [CrossRef]

38. Yang, C.L.; Wang, J.N.; Ge, W.K.; Guo, L.; Yang, S.H.; Shen, D.Z. Enhanced ultraviolet emission and optical properties in polyvinyl pyrrolidone surface modified ZnO quantum dots. J. Appl. Phys. 2001, 90, 4489-4493. [CrossRef] 
39. Sahu, D.R.; Huang, J.L. The properties of $\mathrm{ZnO} / \mathrm{Cu} / \mathrm{ZnO}$ multilayer films before and after annealing in the different atmosphere. Thin Solid Films 2007, 516, 208-211. [CrossRef]

40. Shi, S.; Dang, Z.M.; Xu, J.; Li, L.; Hu, G.H. Surface-related emissions and ferromagnetism in undoped ZnO nanorods. Superlattices Microstruct. 2013, 64, 375-387. [CrossRef]

41. Singh, T.; Lehnen, T.; Leuning, T.; Sahu, D.; Mathur, S. Thickness dependence of optoelectronic properties in ALD grown ZnO thin films. Appl. Surf. Sci. 2014, 289, 27-32. [CrossRef]

42. Anandan, S.; Muthukumaran, S. Microstructural, crystallographic and optical characterizations of Cu-doped $\mathrm{ZnO}$ nanoparticles co-doped with Ni. J. Mater. Sci. Mater. Electron. 2015, 26, 4298-4307. [CrossRef]

43. Ben Elkamel, I.; Hamdaoui, N.; Mezni, A.; Ajjel, R.; Beji, L. Synthesis and characterization of Cu doped ZnO nanoparticles for stable and fast response UV photodetector at low noise current. J. Mater. Sci. Mater. Electron. 2019, 4, 1-11. [CrossRef]

44. Abinaya, C.; Mayandi, J.; Osborne, J.; Frost, M.; Ekstrum, C.; Pearce, J.M. Inhibition of growth of S. epidermidis by hydrothermally synthesized $\mathrm{ZnO}$ nanoplates. Mater. Res. Express 2017, 4, 1-8. [CrossRef]

45. Akhavan, O.; Azimirad, R.; Safa, S.; Hasani, E. $\mathrm{CuO} / \mathrm{Cu}(\mathrm{OH})_{2}$ hierarchical nanostructures as bactericidal photocatalysts. J. Mater. Chem. 2011, 21, 9634-9640. [CrossRef]

46. Lazcano, P.; Batzill, M.; Diebold, U.; Häberle, P. Oxygen adsorption on Cu ZnO (0001) -Zn. Phys. Rev. B Condens. Matter Mater. Phys. 2008, 77, 1-10.

47. Tang, G.; Shi, X.; Huo, C.; Wang, Z. Room temperature ferromagnetism in hydrothermally grown $\mathrm{Ni}$ and $\mathrm{Cu}$ co-doped ZnO nanorods. Ceram. Int. 2013, 39, 4825-4829. [CrossRef]

48. Lim, J.H.; Lee, S.M.; Kim, H.S.; Kim, H.Y.; Park, J.; Jung, S.B.; Park, G.C.; Kim, J.; Joo, J. Synergistic effect of Indium and Gallium co-doping on growth behavior and physical properties of hydrothermally grown $\mathrm{ZnO}$ nanorods. Sci. Rep. 2017, 7, 1-10. [CrossRef]

49. Lv, J.; Zhu, Q.; Zeng, Z.; Zhang, M.; Yang, J.; Zhao, M.; Wang, W.; Cheng, Y.; He, G.; Sun, Z. Enhanced photocurrent and photocatalytic properties of porous $\mathrm{ZnO}$ thin film by Ag nanoparticles. J. Phys. Chem. Solids 2017, 111, 104-109. [CrossRef]

50. Khan, W.; Ajmal, H.M.S.; Khan, F.; Huda, N.U.; Kim, S.-D. Induced Photonic Response of ZnO Nanorods Grown on Oxygen Plasma-Treated Seed Crystallites. Nanomater. (Basel, Switzerland) 2018, 8, 1-11. [CrossRef]

51. Liu, Q.; Gong, M.; Cook, B.; Ewing, D.; Casper, M.; Stramel, A.; Wu, J. Fused Nanojunctions of Electron-Depleted ZnO Nanoparticles for Extraordinary Performance in Ultraviolet Detection. Adv. Mater. Interfaces 2017, 4, 1-11. [CrossRef]

52. Leelavathi, A.; Madras, G.; Ravishankar, N. Origin of enhanced photocatalytic activity and photoconduction in high aspect ratio ZnO nanorods. Phys. Chem. Chem. Phys. 2013, 15, 10795-10802. [CrossRef]

53. Melnick, D.A. Zinc Oxide Photoconduction, an Oxygen Adsorption Process. J. Chem. Phys. 1957, 26, 1136-1146. [CrossRef]

54. Liu, L.; Mei, Z.; Tang, A.; Azarov, A.; Kuznetsov, A.; Xue, Q.K.; Du, X. Oxygen vacancies: The origin of n-type conductivity in ZnO. Phys. Rev. B 2016, 93, 1-10. [CrossRef]

55. Khan, F.; Khan, W.; Kim, J.H.; Huda, N.U.; Salman Ajmal, H.M.; Kim, S.D. Oxygen desorption kinetics of ZnO nanorod-gated AlGaN/GaN HEMT-based UV photodetectors. AIP Adv. 2018, 8. [CrossRef]

56. Sarkar, S.; Basak, D. Defect controlled ultra high ultraviolet photocurrent gain in Cu-doped ZnO nanorod arrays: De-trapping yield. Appl. Phys. Lett. 2013, 103, 1-9. [CrossRef]

57. West, C.; Robbins, D.J.; Dean, P.J.; Hayes, W. The luminescence of copper in zinc oxide. Phys. B+C 1983, 116, 492-499. [CrossRef]

58. Jun, J.H.; Seong, H.; Cho, K.; Moon, B.M.; Kim, S. Ultraviolet photodetectors based on ZnO nanoparticles. Ceram. Int. 2009, 35, 2797-2801. [CrossRef]

59. Pimentel, A.; Ferreira, S.; Nunes, D.; Calmeiro, T.; Martins, R.; Fortunato, E. Microwave Synthesized ZnO Nanorod Arrays for UV Sensors: A Seed Layer Annealing Temperature Study. Materials (Basel) 2016, 9, 299. [CrossRef]

60. Dong, Y.; Zou, Y.; Song, J.; Li, J.; Han, B.; Shan, Q.; Xu, L.; Xue, J.; Zeng, H. An all-inkjet-printed flexible UV photodetector. Nanoscale 2017, 9, 8580-8585. [CrossRef]

61. Lai, W.-C.; Chen, J.-T.; Yang, Y.-Y. Optoelectrical and low-frequency noise characteristics of flexible $\mathrm{ZnO}-\mathrm{SiO} 2$ photodetectors with organosilicon buffer layer. Opt. Express 2013, 21, 9643. [CrossRef] 
62. Khan, F.; Khan, W.; Kim, S.-D. High-Performance Ultraviolet Light Detection Using Nano-Scale-Fin Isolation AlGaN/GaN Heterostructures with ZnO Nanorods. Nanomaterials 2019, 9, 440. [CrossRef]

63. Sugumar, R.; Angappane, S. Influence of substrate heating and annealing on the properties and photoresponse of manganese doped zinc oxide thin films. Superlattices Microstruct. 2017, 110, 57-67. [CrossRef]

(C) 2019 by the authors. Licensee MDPI, Basel, Switzerland. This article is an open access article distributed under the terms and conditions of the Creative Commons Attribution (CC BY) license (http://creativecommons.org/licenses/by/4.0/). 